\title{
Parametric study of multiphase flow in potential Barents Sea pipelines from Fedyn Arch to shore
}

\author{
A. Minikeeva ${ }^{1,2}$ \& O. T. Gudmestad ${ }^{2}$ \\ ${ }^{1}$ FMC Technologies, Oslo, Norway \\ ${ }^{2}$ University of Stavanger, Stavanger, Norway
}

\begin{abstract}
The Arctic region is believed to be one of the most important remaining petroleum provinces. As part of the Arctic potential, the Barents Sea represents an opportunity to develop a new European petroleum province. This paper is focused on the Fedyn Arch in the former disputed area, which potentially is one of the biggest gas fields in the Barents Sea. The paper starts by outlining the Barents Sea geological conditions to make an overall picture of potential hydrocarbon reserves of this area. Hydrocarbon transportation scenarios of the Fedinskiy High field development will be discussed taking into account suitable sites for a potential onshore treatment terminal and potentially an LNG plant. Depending on various factors the question of transport solution becomes significant, and its costs could reach billions of dollars. One of the most costeffective solutions for the development of offshore fields is the use of subsea to shore concept. The objective of the study is to analyze how a flow rate variation in a gas condensate system influences the water accumulation (HOLDUP) along the pipeline as well as on flow regime changes and overall pressure loss. Possible scenarios of arrival facilities are discussed in detail based on existing and planned onshore infrastructures. According to the suggested scenarios multiphase simulation will be carried out by the OLGA simulator. Due to special environmental conditions (potential sub-zero temperatures at the seabed) in the Arctic regions, such as in the Barents Sea, it is important to consider the risk of hydrate formation along the pipeline.

Keywords: offshore field development, multiphase flow, pipeline, flow assurance.
\end{abstract}




\section{Introduction}

A recent agreement between Russia and Norway regarding the state borders in the former disputed area, so called "grey zone” (Figure 1), was reached in 2011. It was the main result of extensive negotiations between two countries over the last 40 years. Preliminary estimates of the potential resources in the previously "grey zone" are expected to be 10-12 billion boe or it may potentially be as high as 18 billion boe [1]. Therefore, the area could become a frontier region of oil and gas development, which could require the building of massive onshore and offshore infrastructure.

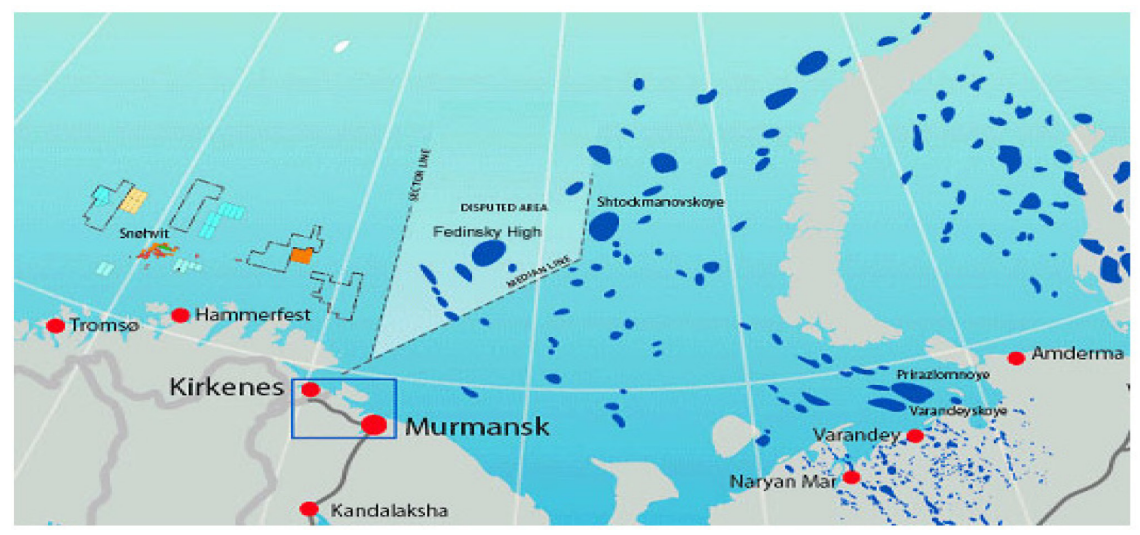

Figure 1: $\quad$ Barents Sea - former disputed area [2].

\section{Feasibility of Fedyn Arch development}

\subsection{Geological conditions}

Due to the 40-year long-term negotiations between Russia and Norway over the disputed area in the Barents Sea no exploration was conducted in that region, so as not to interfere with a moratorium on production and exploration until the border was defined. Thus, there are no official assessments of the "grey zone" potential resources. However, the Russian side carried out some seismic surveys in that area during the 1980s and identified several structures, among which a huge basement induced uplift some $130 \mathrm{~km}$ in diameter, the Fedinskiy High (Hjalmar Johansen High) (Figure 2).

There are several basins and regions within the Barents Sea. The main structural elements in the disputed area are from south to north: the Finnmark Platform, the Tiddly Bank Basin, the Hjalmar Johansen High (Fedunskiy High), and the Nordkapp basin, the Bjarmeland Platform, the Central Bank High and the Hopen/Persey High. The Fedunskiy High and the eastern of the Nordkapp Basin are potentially the two most attractive areas for future exploration [3]. 


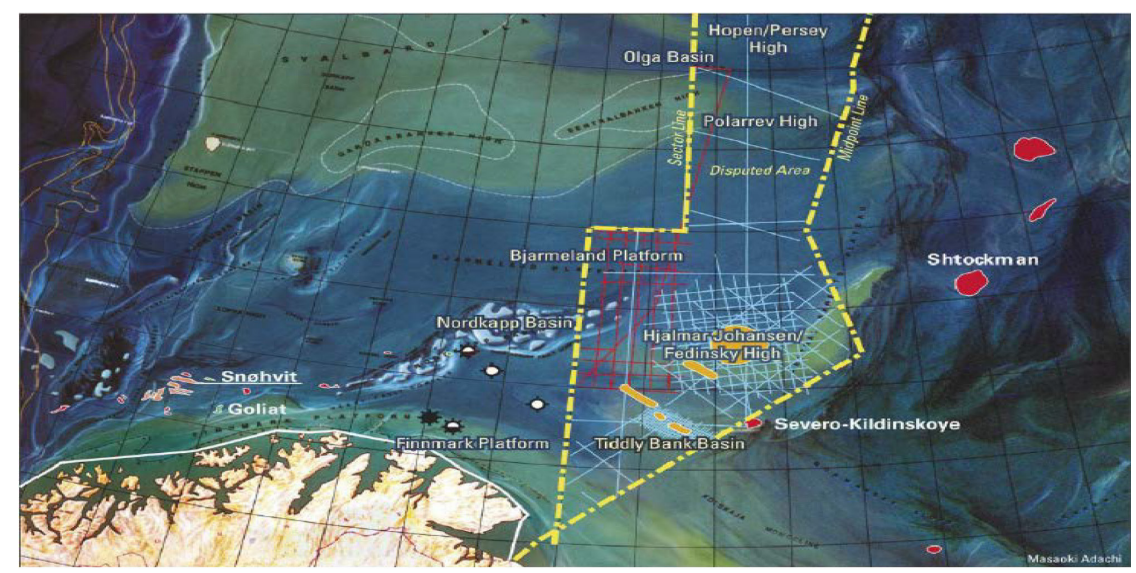

Figure 2: $\quad$ Seismic data of disputed area. Source: [3].

The main discoveries in the Norwegian sector of the Barents Sea are the Snøhvit gas field which is located in the Hammerfest Basin and consists of the Askeladd West, Askeladd Central, Askeladd, Albatross, Snøhvit North, Beta and Albatross South discoveries as well as the recent discoveries of Goliat and Skrugard fields. The Norwegian Barents Sea reservoirs that are now being developed are all consisting of Lower to Middle Jurassic sandstones. While the giant Shtokman gas field in the Russian sector of the Barents Sea is somewhat younger and the hydrocarbons are trapped in marine sandstones of Middle Jurassic [4].

Based on the field deposits that have been proven in both Russian and Norwegian sectors there are high expectations for potential hydrocarbon discoveries in the "grey zone" area. A lot of experts believe that this area can contain huge reserves of oil and gas and that the Russian hydrocarbon discovery in the Jurassic to the east might be continued into the former disputed area. However the presence of the significant transition from the Jurassic aged sediment fields in the Barents basins up on to the platforms make this statement highly questionable.

Due to the Pandora discovery in the southern Nordkapp basin which contained Triassic fluvial sands, it is believed that the main prospects of the Tiddly bank and the Nordkapp basins (Figure 2) sediments are in Triassic sands, which is trapped in the salt pillows. It is also presumed that there are no Tertiary aged sediments in the former disputed area, although Paleozoic and Mesozoic aged rocks subcrop below the Quaternary is presented in the former "grey zone" area.

Clastic sedimentation from the Triassic is the most attractive Mesozoic target for the hydrocarbon exploration on the platforms. Gas-bearing Triassic fluvial sands have been found in the Severo-Kildinskoye gas discovery structure, right east to the border of the former disputed area [3]. The Norwegian Petroleum Directorate (NPD) has published information about major geological features of the Norwegian part of the Barents Sea, which shows that most of the plays are 
cut straight along the border of the former grey zone. Eight out of 23 plays are confirmed, which makes it reasonable to believe that the former disputed area could contain a significant amount of petroleum resources. Nevertheless, there are also some unsuccessful discoveries on the Norwegian sector of the Barents Sea. The 3D seismic survey on the Finnmark platform close to the former "grey zone" area established a huge stratigraphic trap. A drilled well was later abandoned as a dry well. Thus, the key question is then how much one should expect to discover in the former disputed area.

According to the Russian Ministry of Natural Resources the former disputed area might contain 6.4 billion tons of oil equivalents, corresponding to 50 billion boe [5]. However, this area has no official proven reserves and the reliability of the Russian estimates is doubtful. The work presented in this paper focuses particularly on the largest deposit, the Fedunskiy High potential reserves, which have been widely discussed and have different assessments. Its resources are expected to be around 10-12 billion boe, or may potentially be as high as 18 billion boe [1]. Despite some disappointments, the overall expectation for hydrocarbon discoveries in the Barents Sea remains high, especially in the previously disputed area. The Norwegian Government have announced that seismic surveys started north in the former disputed zone during the summer of 2012 and will continue into 2013 [6]. These surveys will provide important knowledge about the oil and gas potential reserves in the Barents Sea.

\section{Potential sites for LNG terminal}

\subsection{Evaluation of possible sites - Teriberka}

One of the possible locations of future LNG plant for Fedyn Arch in the Barents Sea is suggested to be in Teriberka, which is located 100 kilometres northeast of Murmansk, Russia. Teriberka has been chosen as the operating hub for a potential Shtokman field development.

The gas together with condensate will arrive from the offshore via a trunk line. The landfall will be located on the northern shore of the Kola Peninsula in Opasova bay.

\subsection{Evaluation of possible sites - Kirkenes}

Another promising area for a future processing plant for Fedyn Arch gas is believed to be in Kirkenes. Its harbour has adequate water depths, where large sections of the fairway in the sea area are deeper than 40 meters. It is shallower close to land, but vessels are close to the shore at depths of 20 meters. The Slambanken area is $110,000 \mathrm{~m}^{2}$ and the downtown Coastal Steamer Terminal has an area of $120,000 \mathrm{~m}^{2}$. The conditions at the entrance to the harbour are good. There is some ice during parts of the winter. Conditions are calm in the harbour. During the approach to Kirkenes harbour the depth is generally greater than 30 meters. The Kirkenes area is suitable as a "potential site” for an LNG plant. 
There are several sites that comply with the physical requirements for a terminal and in the nearby fjord the 132 square kilometer big island of Skogerøya (Figure 3) is a potential terminal site for Fedyn Arch gas. The Varanger commune has identified this island as the potential location for an LNG terminal.

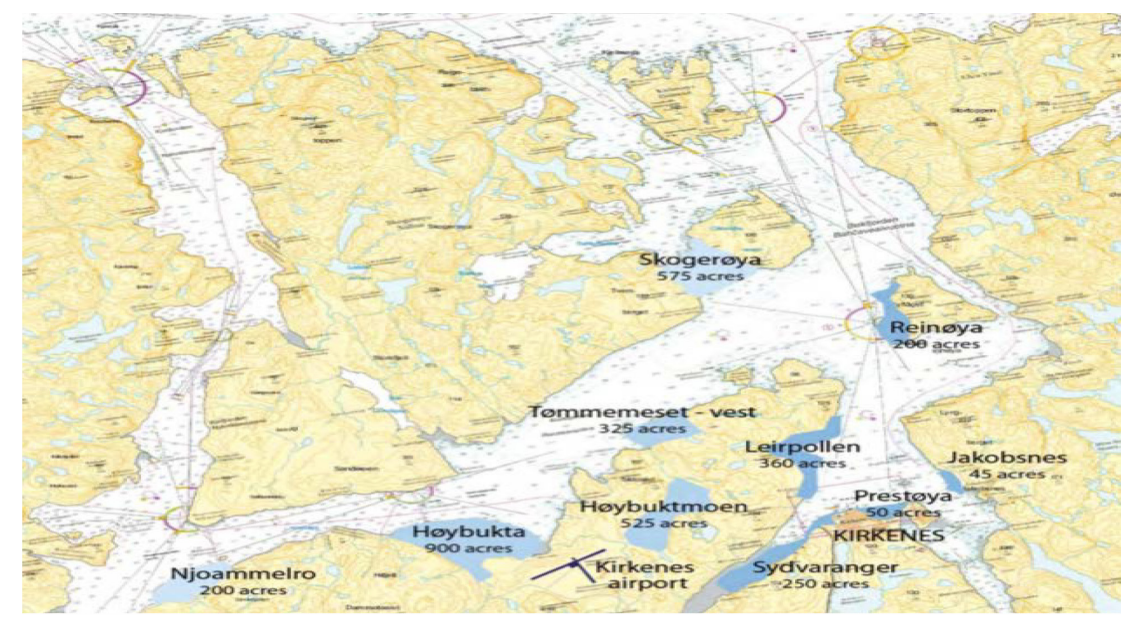

Figure 3: $\quad$ Industrial site areas in Kirkenes area.

\section{Dynamic simulation of multiphase flow}

\subsection{Production data}

PVTsim has been used to characterize the gas condensate composition for Fedyn Arch. For simulation the fluid composition from the Shtokman gas condensate field was used, assuming possible proximity of hydrocarbon-bearing formations in that area.

Table 1 show the gas composition used in the simulation. The assumed fluid was defined as a "Plus fraction" fluid in PVTsim. Fresh water was added to the assumed reservoir fluid until saturation at initial reservoir conditions (Table 2). As the reservoir depletes, more water will be saturated in the reservoir fluid. The resulting hydrate curve and phase envelope are shown in Figures 4 and 5. The hydrate equilibrium curve indicates the hydrate formation region (to the left of the curve). Therefore for hydrate prevention one should stay outside of the hydrate equilibrium region. 
Table 1: $\quad$ Fluid composition.

\begin{tabular}{|c|c|}
\hline Component & Mol, \% \\
\hline H20 & 0.133 \\
\hline N2 & 1.859 \\
\hline CO2 & 0.300 \\
\hline C1 & 95.198 \\
\hline Component & Mol, $\%$ \\
\hline C2 & 1.629 \\
\hline C3 & 0.504 \\
\hline iC4 & 0.150 \\
\hline nC4 & 0.075 \\
\hline iC5 & 0.038 \\
\hline nC5 & 0.019 \\
\hline C6 & 0.020 \\
\hline C7 & 0.021 \\
\hline C8 & 0.012 \\
\hline C9 10 & 0.006 \\
\hline C11 & 0.005 \\
\hline C12+C19 & 0.026 \\
\hline & 0.01 \\
\hline
\end{tabular}

Table 2: $\quad$ Fedyn Arch assumed key data.

\begin{tabular}{|c|c|}
\hline Parameter & Value \\
\hline Initial reservoir pressure & 250 bara \\
\hline Initial reservoir temperature & $55^{\circ} \mathrm{C}$ \\
\hline Outlet pressure & 60 bara \\
\hline Seabed temperature & $-1.8^{\circ} \mathrm{C}$ \\
\hline
\end{tabular}

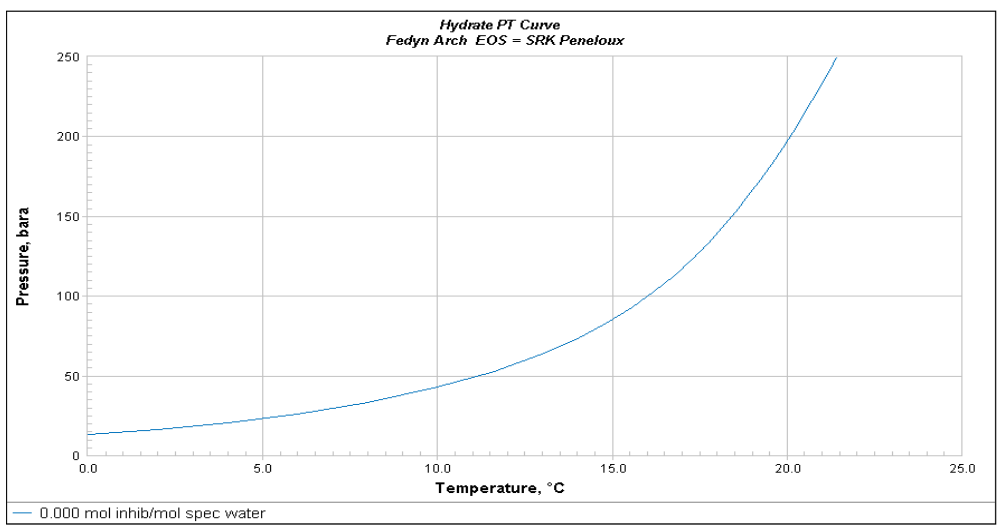

Figure 4: Hydrate equilibrium curve for the Fedyn Arch field, saturated with fresh water at reservoir conditions. 


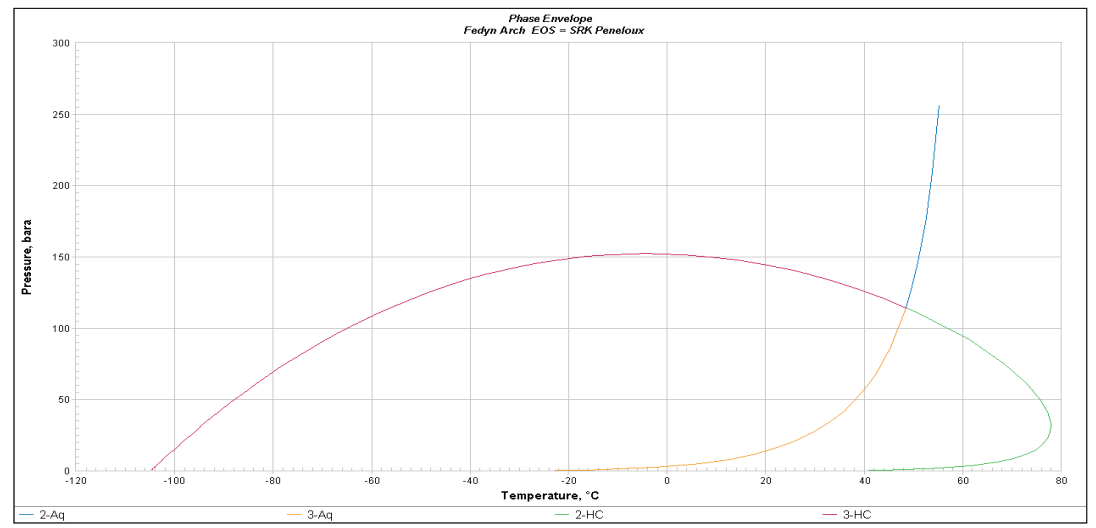

Figure 5: Phase envelope for gas composition used in OLGA model, saturated with fresh water at 250 bara and $55^{\circ} \mathrm{C}$.

\subsection{Geometry input data}

Two potential sites were identified for future LNG plants, as being the following: Kirkenes area (Norway) and Murmansk region, Teriberka (Russia). In order to make further evaluation of pipeline route configurations the following approximate coordinates of the field were used:

- Latitudinal $72^{\circ} 30^{\prime} 00.00^{\prime \prime} \mathrm{N}$

- Longitudinal $36^{\circ} 00^{\prime} 00.00^{\prime \prime} \mathrm{E}$

Possible pipeline profiles from the Fedyn Arch to Kirkines and to Teriberka were derived from nautical charts. The potential trunkline geometries were discretized into simplified profiles for the OLGA simulation model. The resulting trunkline profiles to Kirkines and Teriberka are shown in Figures 6 and , respectively. Please note that the simplified pipeline route profiles used, do not take into account obstructions, free spans and seabed features (rocks, mud slides, iceberg scars and etc.).

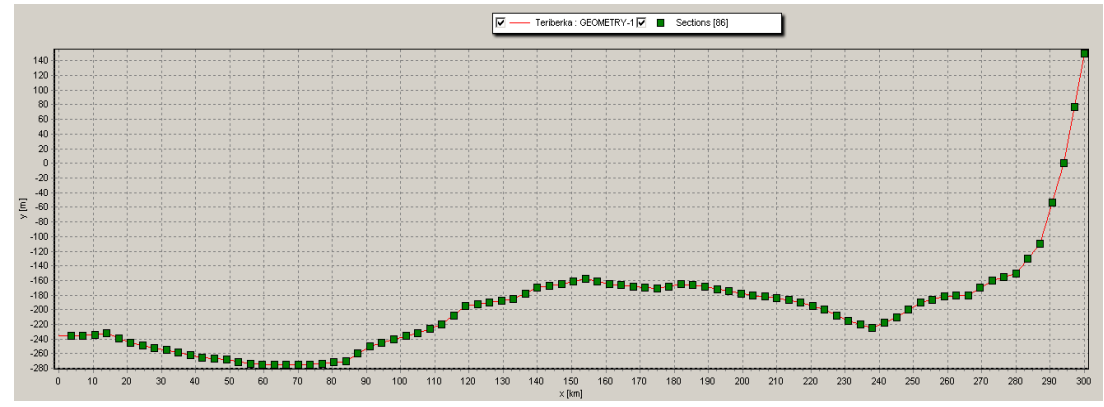

Figure 6: Trunkline profile from Fedyn Arch to Teriberka. 


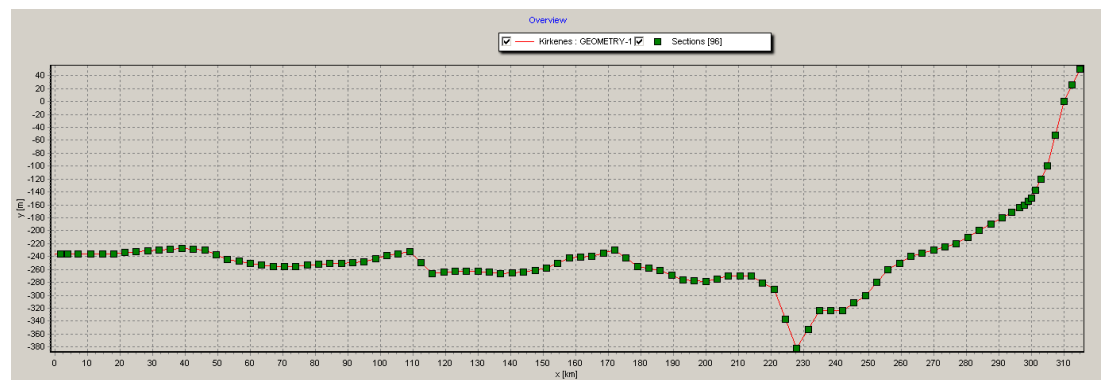

Figure 7: $\quad$ Trunkline profile from Fedyn Arch to Kirkenes.

Both trunkline profiles are characterized by significant differences in elevations of the seabed. The maximum depth of the sea along the route to Teriberka is 250 meters. The final section of the pipeline is characterized be a very steep ascent. Estimated route length is 300 kilometres. The maximum sea depth along the Kirkenes route is around 400 meters and the estimated route length is 310 kilometres.

Table 3: $\quad$ OLGA model pipe material input data.

\begin{tabular}{|c|c|c|c|}
\hline Material & $\begin{array}{c}\text { Density } \\
{\left[\mathrm{kg} / \mathrm{m}^{3}\right]}\end{array}$ & $\begin{array}{c}\text { Conductivity } \\
{[\mathrm{W} / \mathrm{mK}]}\end{array}$ & $\begin{array}{c}\text { Heat Capacity } \\
{[\mathrm{J} / \mathrm{kgC}]}\end{array}$ \\
\hline Steel & 7850 & 45 & 460 \\
\hline Concrete & 2250 & 2 & 880 \\
\hline
\end{tabular}

The diameter of the pipelines is assumed to be 36 inch. The pipe wall properties used as input to the OLGA model are summarized in Table 2.

\subsection{Case study}

The objective of the study is to evaluate how the trunkline production capacity influences on the pipeline flow regime, holdup and overall pressure loss. Sensitivity analyses will be carried out for different production flow rates, such as:

- $35 \mathrm{MSm}^{3} / \mathrm{d}$

- $17 \mathrm{MSm}^{3} / \mathrm{d}$

- $8 \mathrm{MSm}^{3} / \mathrm{d}$

In the following, results for both transportation scenarios (Section 3) will be presented. Multiphase simulation will be based on the assumed fluid composition as well as the simplified pipeline profiles.

\subsubsection{Fedyn Arch-Kirkenes}

The overall results for the flow rate of $35 \mathrm{MSm}^{3} / \mathrm{d}$ are shown in Figure 8. The pipeline is dominated by a stratified flow regime (see the black line in the graph 
in Figure 8). Assuming a seafloor temperature of -1.8 degrees Celsius, we find that the temperature in the pipeline close to shore falls below zero, which should certainly be taken into account in future planning of the trunkline. The water accumulation along the pipeline is, however, relatively small. Please note that the overall heat transfer coefficient of the trunkline was calculated to $22 \mathrm{~W} / \mathrm{m}^{2} \mathrm{~K}$ at steady state condition.

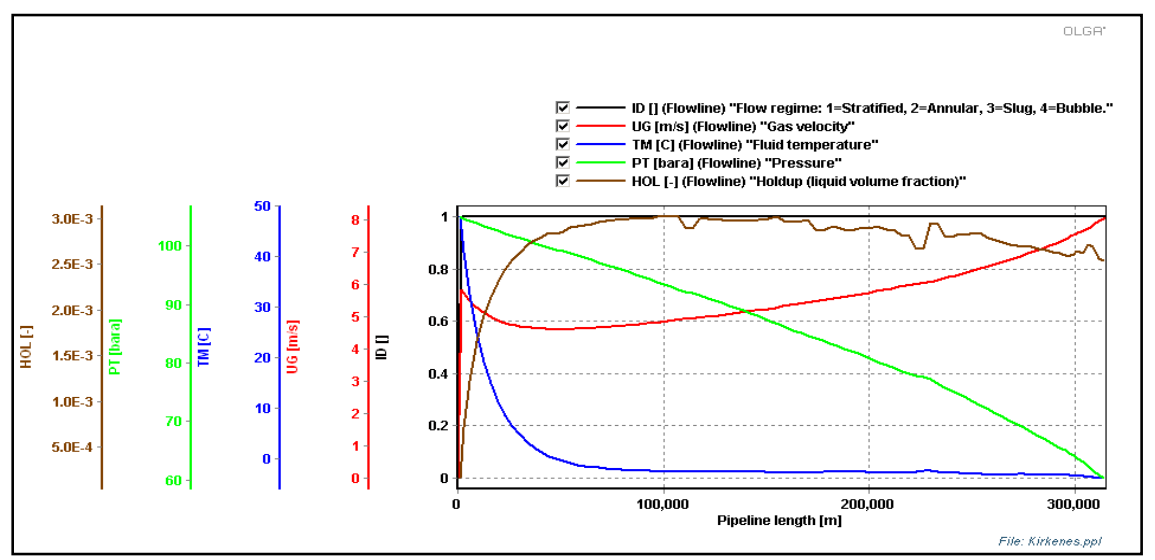

Figure 8: $\quad$ Fedyn Arch-Kirkenes. Flow rate $35 \mathrm{MSm}^{3} / \mathrm{d}$.

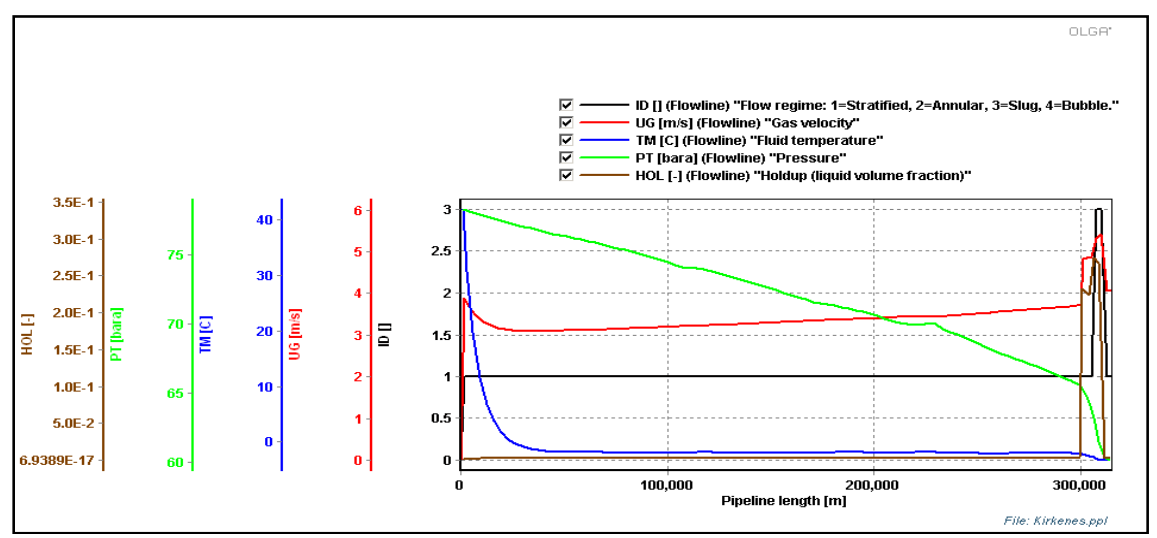

Figure 9: $\quad$ Fedyn Arch-Kirkenes. Flow rate $17 \mathrm{MSm}^{3} / \mathrm{d}$.

The following results were obtained for the $17 \mathrm{MSm}^{3} / \mathrm{d}$ flow rate case (Figure 9). The pipeline transportation in this case will require approximately 80 atmospheres. Thus, an insignificant pressure drop can be seen compared to the first case. The gas volume in the pipe decreases, and the velocity of the gas close to shore is no longer sufficient to drag the liquid up. Hence, the pipeline is filled with liquid; close to shore up to $35 \%$. The accumulation of liquid influences on 
the flow regime close to the shore, therefore, a slug flow regime is formed at end of the trunkline.

The resulting graphs for the third case $\left(8 \mathrm{MSm}^{3} / \mathrm{d}\right)$ are shown in Figure 10 . Further reduction of the gas velocity leads to water accumulation up to $50 \%$. From Figure 10 it can be seen that water builds up at the lower parts of the pipeline (see the purple line- pipeline geometry). Hence, the slug flow regime is developing further.

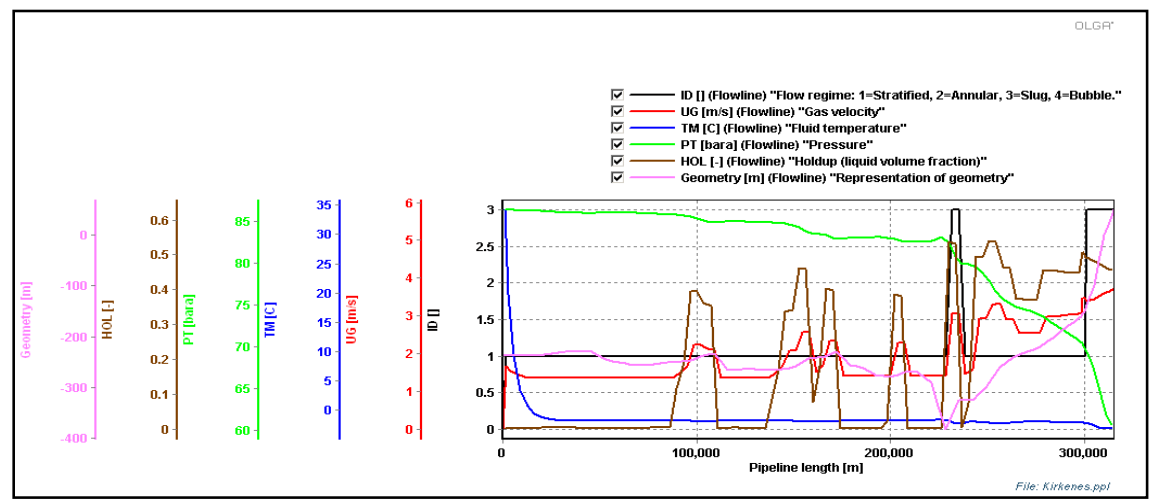

Figure 10: Fedyn Arch-Kirkenes. Flow rate 8 MSm³/d.

\subsubsection{Fedyn Arch-Teriberka}

The overall results of pressure and temperature distribution, as well as flow regime and water volume fraction along the pipeline is shown in Figure 11. The pipeline is dominated by a stratified flow regime. The temperature falls below zero, which might lead to the hydrate formation in the pipeline and will be further discussed in Section 5. The water accumulation along the pipeline is

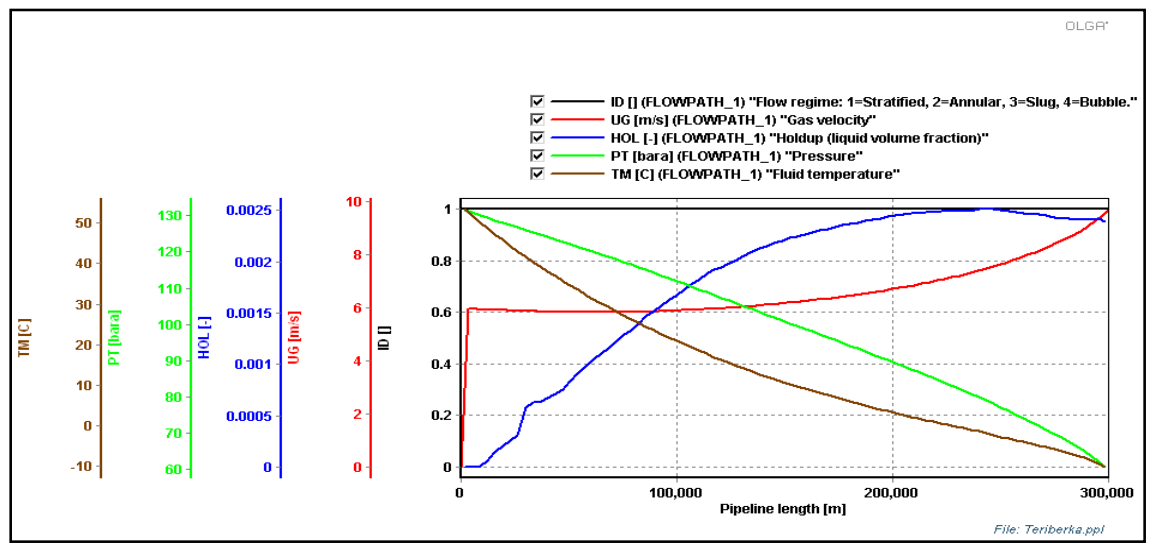

Figure 11: Fedyn Arch-Teriberka. Flow rate $35 \mathrm{MSm}^{3} / \mathrm{d}$. 
relatively small, $0.8 \%$. Please note that the overall heat transfer coefficient of the trunkline was calculated to $20 \mathrm{~W} / \mathrm{m}^{2} \mathrm{~K}$ at steady state condition.

Plots in Figure 12 show the results for the $17 \mathrm{MSm}^{3} / \mathrm{d}$ flow rate case. The pipeline transportation in this case will require approximately 85 atmospheres. The flow regime in the pipeline remains stratified. The water accumulation in the pipeline is around $0.9 \%$. Gas velocity is approximately $5.5 \mathrm{~m} / \mathrm{s}$.

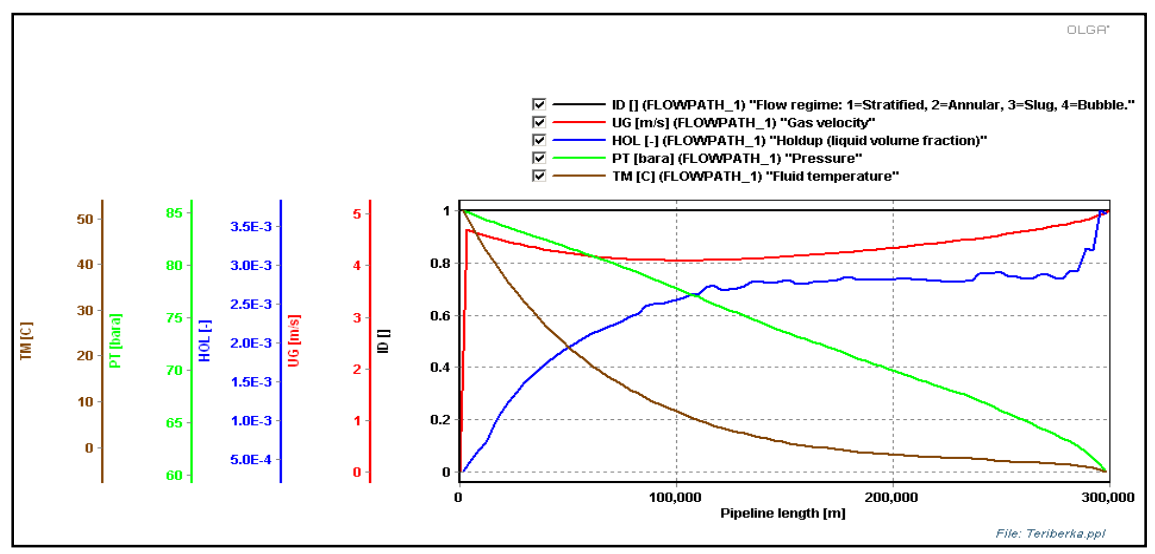

Figure 12: Fedyn Arch-Teriberka. Flow rate $17 \mathrm{MSm}^{3} / \mathrm{d}$.

The resulting graphs for the third case $\left(8 \mathrm{MSm}^{3} / \mathrm{d}\right)$ are shown in Figure 13. The velocity of the gas equals to $4 \mathrm{~m} / \mathrm{s}$, which is not high enough to lift the liquid up, and back-flow of the liquid acquires. Thus, the pipeline fills with water up to $40 \%$. It affects the flow regime changes along the pipeline and the slug flow regime is developing further.

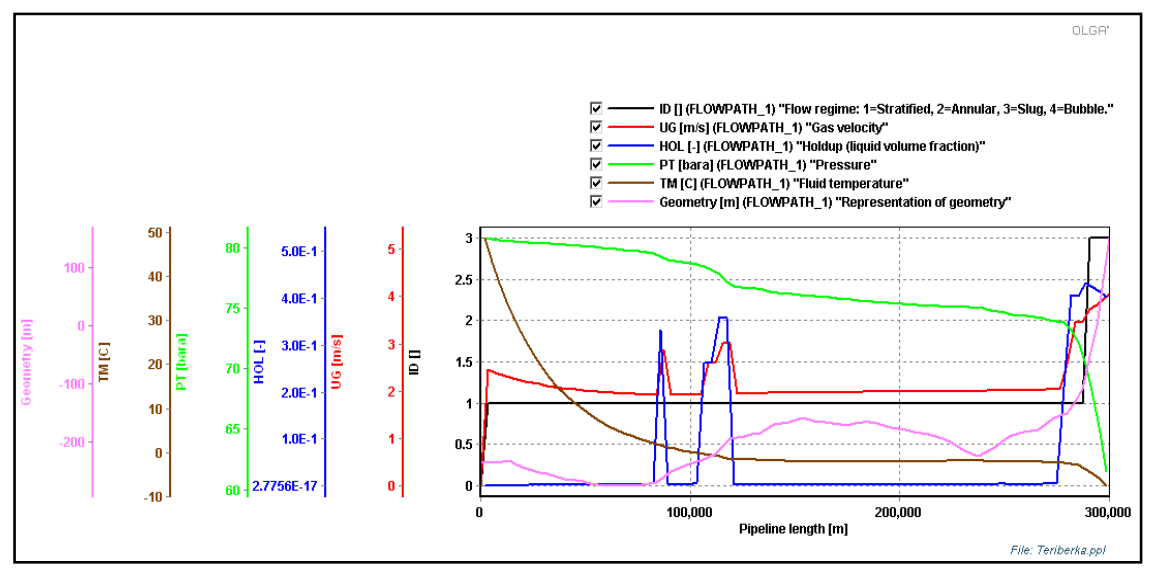

Figure 13: Fedyn Arch-Teriberka. Flow rate $8 \mathrm{MSm}^{3} / \mathrm{d}$. 


\section{Conclusion}

The case studies have been performed using OLGA simulator software to predict potential flow assurance challenges during the multiphase transportation for two scenarios of LNG location plants: Teriberka, Russia and Kirkenes, Norway. Due to the lack of information about the former disputed area several assumptions have been made, with relation to the fluid properties and the topography of the seabed. The sensitivity analysis for different flow rates show that the gas velocities below a critical value may lead to accumulation of liquid along the pipeline. It should be also noted that the water accumulation significantly depends on the pipeline profile. Please note that simplified pipeline geometries were used which might lead to some underestimation of the water accumulation and pressure losses especially at low flow rates. Hydrate control methods, such as chemicals, passive heat controls and etc. have not been considered in the analysis. Pressure and temperature distribution graphs for both cases of hydrocarbon transportation were also predicted, taking into account fluid properties and the pipeline route. There is a huge temperature impact when dealing with development in the Arctic regions such as Barents Sea. The worst case scenario of $\mathrm{a}-1.8^{\circ} \mathrm{C}$ ambient temperature was used for the simulation. The resulting temperature distributions along the pipeline, for both cases of fluid transportation, indicate very low values, especially close to the shore. From Figure 4 of the hydrate equilibrium curve can be seen that without hydrate control methods, the operational process is in the hydrate formation area. Hydrates can cause serious impediment to the production process, as it may take weeks or months to clear the system, which of course would lead to significant economical loses. Therefore, attention must be paid to ensure a reliable and stable operational process of hydrocarbon transportation.

\section{References}

[1] Bulakh M., Zolotukhin A.B., Gudmestad O.T., "Fedyn Arch - the promising zone for HC reserves in the Barents Sea. Agreement between Russia and Norway” SPE paper - 149654, 2011

[2] http://barentsobserver.com/en/articles/zarubezhneft-wants-fedinsky-high

[3] Ræstand N., Sagex "Barents Sea Nondiscussed Area” GEO ExPro, Issue 2 Volume 6, March 2006

[4] Larssen, G. B., Elvebakk, G., Henriksen, L.B., et al., "Upper Palaeozoic lithostratigraphy of the southern part of the Norwegian Barents Sea” Norges geologiske undersøkelse Bulletin 444 (2005), pp. 3-45

[5] http://www.finnmarken.no/finnmarkdagblad/nyheter/article5093070.ece

[6] http://www.regjeringen.no/en/dep/smk/press-center/Press-releases/2012/ norway-to-start-seismic-surveys-in-the-b.html?id=671815 